Case Report

\title{
Mutation in the SLC2A9 Gene: A New Family with Familial Renal Hypouricemia Type 2
}

\author{
Christian Maalouli $\mathbb{D}^{1},{ }^{1}$ Karin Dahan, ${ }^{2,3}$ Arnaud Devresse, ${ }^{1}$ and Valentine Gillion ${ }^{1}{ }^{1}$ \\ ${ }^{1}$ Division of Nephrology, Cliniques Universitaires Saint-Luc, Université Catholique de Louvain, Brussels, Belgium \\ ${ }^{2}$ Division of Human Genetics, Cliniques Universitaires Saint-Luc, Université Catholique de Louvain, Brussels, Belgium \\ ${ }^{3}$ Center of Human Genetics, Institut de Pathologie et de Génétique, Charleroi, Belgium
}

Correspondence should be addressed to Valentine Gillion; valentine.gillion@uclouvain.be

Received 7 June 2021; Accepted 8 September 2021; Published 24 September 2021

Academic Editor: Salih Kavukcu

Copyright ( $\odot 2021$ Christian Maalouli et al. This is an open access article distributed under the Creative Commons Attribution License, which permits unrestricted use, distribution, and reproduction in any medium, provided the original work is properly cited.

\begin{abstract}
Familial renal hypouricemia is a rare genetic disorder characterized by a defect in renal tubular urate reabsorption. Some patients present with exercise-induced acute kidney injury and nephrolithiasis. Type II is caused by mutations in the SLC2A9 gene. Here, we report the case of a young patient who developed acute kidney injury after exercise secondary to familial renal hypouricemia type II. The same mutation was found in other asymptomatic members of his family. We review the medical literature on this condition. This case highlights the importance of considering uric acid disorders in the work-up of acute kidney injury after exercise.
\end{abstract}

\section{Introduction}

Hypouricemia may be caused by decreased uric acid production or increased uric acid clearance [1-4]. The latter may be due decreased renal tubular reabsorption secondary to acquired disorders such as Fanconi syndrome or inherited disorders such as familial renal hypouricemia (RHUC) [1-6]. Unlike hyperuricemia and gout, hypouricemia has been thought as a disorder with no clinical significance. However, individuals with RHUC may present with exercise-induced acute kidney injury and nephrolithiasis [1-10]. Here, we report the case of a patient who developed acute kidney injury after strenuous exercise. The work-up has led to the discovery of a new family with RHUC type II.

\section{Case Presentation}

A 20-year-old man presented to the nephrology department with acute pain of both flanks which started after a physical exercise at school. His past medical history was unremarkable. He was not taking any medications or illicit drugs, and he denied smoking and consuming alcohol.
There was no abnormal finding in his physical examination. Vital signs were normal. Laboratory tests on admission showed acute kidney injury with a creatine kinase level of only twice the upper limit of the normal (Table 1). Urinalysis was bland, and the proteinuria was within the range (Table 1). Contrast-enhanced computed tomography showed decreased enhancement of the kidneys without any abnormality of the vessels and showed no urolithiasis. After conservative therapy including intravenous fluid administration, the renal function recovered gradually and returned to the normal at the fourth day after admission.

The patient reported that he was admitted 4 months ago in the emergency room of another hospital for a similar pain which occurred also after a strenuous exercise. Although laboratory tests showed acute kidney injury, he was discharged without any further investigation.

Laboratory tests were marked by severe hypouricemia. The elevated fractional excretion of urate $(119 \% ; N<10 \%)$ suggested a highly increased urinary excretion of uric acid with tubular secretion. Blood and urinary tests showed no argument for Fanconi syndrome or syndrome of inappropriate antidiuretic hormone. Interesting enough, severe 
TABLE 1: Laboratory findings.

\begin{tabular}{|c|c|c|c|c|}
\hline Test & & Unit & Value at presentation & Normal range \\
\hline \multirow{15}{*}{ Serum } & CRP & $\mathrm{mg} / \mathrm{l}$ & 3.3 & $<5$ \\
\hline & Creatinine & $\mathrm{mg} / \mathrm{dl}$ & 1.9 & $0.6-1.3$ \\
\hline & Urea & $\mathrm{mg} / \mathrm{dl}$ & 60 & $17-48$ \\
\hline & Uric acid & $\mathrm{mg} / \mathrm{dl}$ & 0.2 & $3.5-7.2$ \\
\hline & Sodium & $\mathrm{mmol} / \mathrm{l}$ & 139 & $135-145$ \\
\hline & Potassium & $\mathrm{mmol} / \mathrm{l}$ & 5.2 & $3.5-5.0$ \\
\hline & Bicarbonate & $\mathrm{mmol} / \mathrm{l}$ & 22 & $23-29$ \\
\hline & Calcium & $\mathrm{mmol} / \mathrm{l}$ & 2.3 & $2.2-2.5$ \\
\hline & Phosphate & $\mathrm{mmol} / \mathrm{l}$ & 0.9 & $0.8-1.45$ \\
\hline & Hemoglobin & $\mathrm{g} / \mathrm{dl}$ & 15.3 & $13-18$ \\
\hline & WBC & $/ \mu \mathrm{l}$ & 12310 & $3500-11000$ \\
\hline & Neutrophils & $/ \mu l$ & 9630 & $1500-6700$ \\
\hline & Platelets & $/ \mu \mathrm{l}$ & 170000 & $150000-450000$ \\
\hline & LDH & $\mathrm{U} / 1$ & 262 & $135-225$ \\
\hline & $\mathrm{CK}$ & $\mathrm{U} / \mathrm{l}$ & 640 & $40-300$ \\
\hline \multirow{7}{*}{ Urine } & RBC & $\mid \mu \mathrm{l}$ & 2 & $<25$ \\
\hline & WBC & $\mid \mu l$ & 20 & $<25$ \\
\hline & Creatinine & $\mathrm{g} / 24 \mathrm{~h}$ & 0.98 & $0.8-2.5$ \\
\hline & Protein & $\mathrm{g} / 24 \mathrm{~h}$ & 0.08 & $<0.15$ \\
\hline & Sodium & $\mathrm{mmol} / 24 \mathrm{~h}$ & 216 & $40-220$ \\
\hline & Potassium & $\mathrm{mmol} / 24 \mathrm{~h}$ & 34 & $25-125$ \\
\hline & Uric acid & $\mathrm{mg} / 24 \mathrm{~h}$ & 234 & $250-750$ \\
\hline
\end{tabular}

Abbreviations: CRP, C-reactive protein; WBC, white blood cell; RBC, red blood cell; LDH, lactate dehydrogenase; CK, creatine kinase.

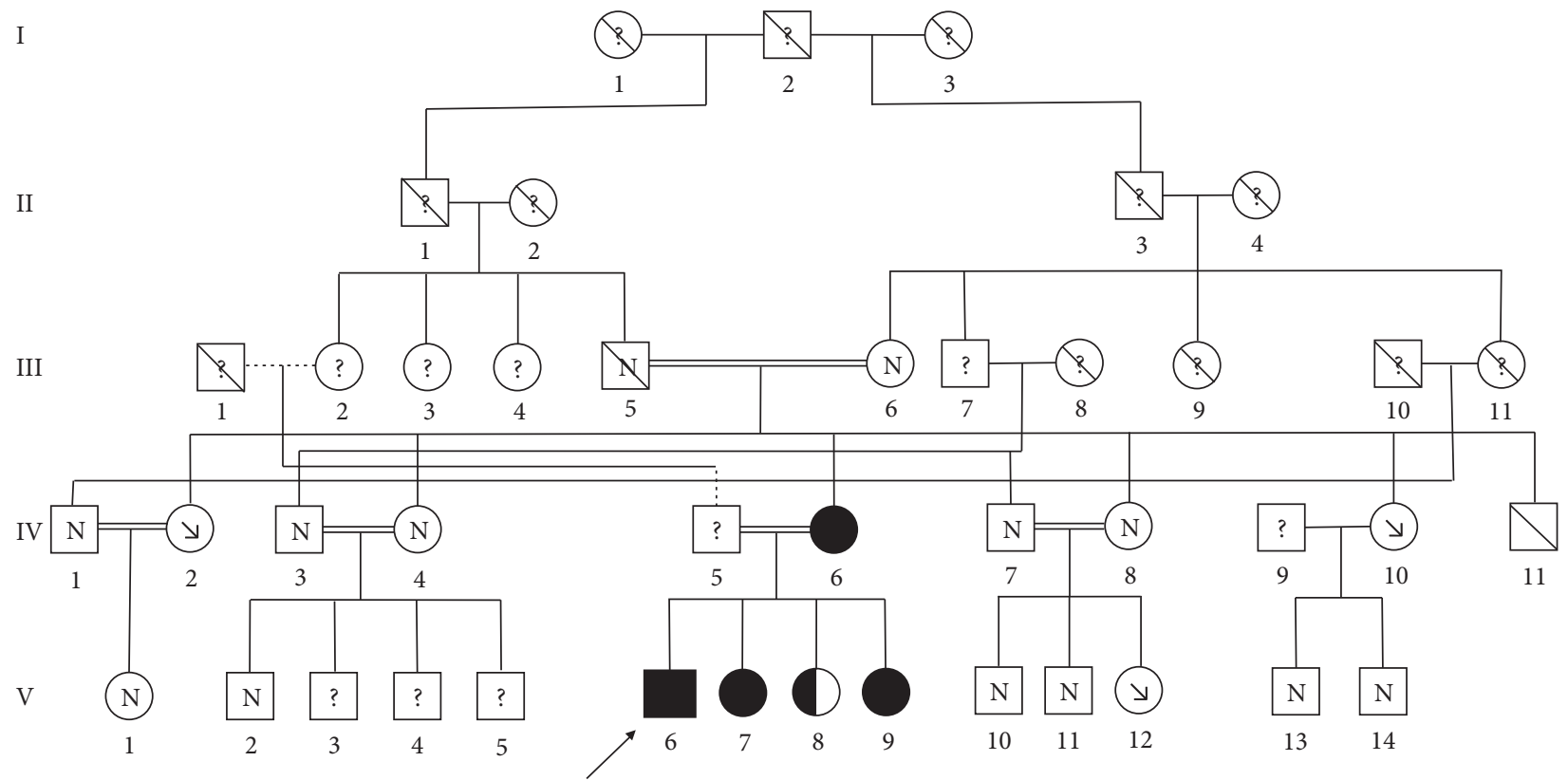

FIgURE 1: Pedigree of the patient. Solid symbols denote family members with homozygous mutation; half-solid denote heterozygous mutation. "N" denotes family members with normal uric acid level; “ $\searrow$ ” denotes severe hypouricemia. "?" denotes family members with no laboratory data. Circles represent female family members, squares represent male family members, and crosses represent dead family members. Double lines indicate consanguineous marriage. Arrow indicates the index patient.

hypouricemia was also found in the laboratory tests of his mother and one of his maternal aunts. The occurrence of two episodes of acute kidney injury following intense exercise with the presence of hereditary severe hypouricemia highly suggested exercise-induced acute kidney injury due to familial renal hypouricemia.
This index patient (V6) is a member of a highly consanguineous Pakistani family with cousin marriages over two successive generations (Figure 1). DNA sequencing by next-generation sequencing identified an homozygosity for a class 5 variant of the SLC2A9 gene (NM_020041.3): c.646G > A, p.(Gly216Arg) confirmed by the Sanger 
technique [5]. Genetic testing of the patient's mother revealed the same homozygous mutation. Severe hypouricemia with the familial homozygous mutation was found in two of his clinically unaffected sisters (V7 and V9). The third sister (V8) is heterozygous for the mutation and is presenting with normal uric acid level. Profound hypouricemia was also measured in one of his aunts (IV2) and one of his cousins (V12). All of these analyses confirmed an autosomal recessive mode of inheritance. Besides the index patient, no medical history was known in all of the family members except his grandfather (III5) who suffered from kidney stones.

\section{Discussion}

RHUC is a rare autosomal recessive genetic disease caused by impaired renal tubular urate transport [1-10]. Less common than type 1 caused by mutations in the SLC22A12 gene encoding the major uric acid transporter URAT1 (OMIM \#220150), type 2 (RHUC2, OMIM \#612076) is caused by mutations in the SLC2A9 gene which encodes GLUT9 [1-5, 7-10]. Its long variant GLUT9L is the only major urate efflux transporter at the basolateral membrane, explaining why homozygous loss-of-function mutations of GLUT9 cause a total defect of uric acid tubular absorption $[1,4,7-9]$. To date, no more than 15 families have been described $[1-4,8,9]$. Although most patients are asymptomatic, the major complications are exercise-induced acute kidney injury (EIAKI) and urolithiasis [1-10]. EIAKI often follows intense exercise and is mostly described in males $[4,8,10]$. It may be secondary to excessive oxidative stress leading to renal vasoconstriction or precipitation of uric acid in the tubules $[1,3,4,8,10]$. When compared to type 1 , patients with type 2 appear to have much higher renal excretion of uric acid and to be more vulnerable for EIAKI and nephrolithiasis $[1,9]$. Measures to prevent these complications include limiting anaerobic physical exercise and maintaining adequate fluid intake [8-10]. Allopurinol may be proposed in specific cases $[2-4,9,10]$.

\section{Data Availability}

The datasets used during the current study are available from the corresponding author on reasonable request.

\section{Consent}

Informed consent was obtained from the patient.

\section{Conflicts of Interest}

The authors declare no conflicts of interest.

\section{References}

[1] D. Dinour, N. K. Gray, S. Campbell et al., "Homozygous SLC2A9 mutations cause severe renal hypouricemia," Journal of the American Society of Nephrology, vol. 21, no. 1, pp. 64-72, 2010.
[2] H. Shen, C. Feng, X. Jin et al., "Recurrent exercise-induced acute kidney injury by idiopathic renal hypouricemia with a novel mutation in the SLC2A9 gene and literature review," BMC Pediatrics, vol. 14, no. 1, p. 73, 2014.

[3] M. Windpessl, M. Ritelli, M. Wallner, and M. Colombi, "A Novel homozygous SLC2A9 mutation associated with renalinduced hypouricemia," American Journal of Nephrology, vol. 43, no. 4, pp. 245-250, 2016.

[4] C. Wang, J. Wang, S. Liu et al., "Idiopathic renal hypouricemia: a case report and literature review," Molecular Medicine Reports, vol. 20, no. 6, pp. 5118-5124, 2019.

[5] B. Stiburkova, J. Taylor, A. M. Marinaki, and I. Sebesta, "Acute kidney injury in two children caused by renal hypouricaemia type 2," Pediatric Nephrology, vol. 27, no. 8, pp. 1411-1415, 2012.

[6] H. O. Kim, C.-G. Ihm, K. H. Jeong et al., "A case report of familial renal hypouricemia confirmed by genotyping ofSLC22A12, and a literature review," Electrolytes \& Blood Pressure, vol. 13, no. 2, pp. 52-57, 2015.

[7] H. Matsuo, T. Chiba, S. Nagamori et al., "Mutations in glucose transporter 9 gene SLC2A9 cause renal hypouricemia," The American Journal of Human Genetics, vol. 83, no. 6, pp. 744-751, 2008.

[8] G. Jeannin, N. Chiarelli, M. Gaggiotti et al., "Recurrent exercise-induced acute renal failure in a young Pakistani man with severe renal hypouricemia and SLC2A9compound heterozygosity," BMC Medical Genetics, vol. 15, no. 1, p. 3, 2014.

[9] A. Peris Vidal, J. Marin Serra, E. Lucas Sáez et al., "Hereditary renal hypouricaemia type 1 and 2 in three Spanish children. Review of published paediatric cases," Nefrologia, vol. 39, no. 4, pp. 355-361, 2019.

[10] Y. Shimizu, K. Wakabayashi, A. Totsuka et al., "Exerciseinduced acute kidney injury in a police officer with hereditary renal hypouricemia," Case Reports in Nephrology and Dialysis, vol. 9, no. 2, pp. 92-101, 2019. 